\title{
Carbohydrate binding properties of mouse embryos
}

\author{
S. Lindenberg* $\ddagger$ S. J. Kimber $\ddagger$ and E. Kallin§
}

* Department of Obstetrics and Gynaecology, Rigshospitalet, University of Copenhagen, Blegdamsvej 9, 2100 Copenhagen, Denmark; †Department of Cell and Structural Biology, University of Manchester, Coupland III Bldg, Coupland St, Manchester M13 9PL, UK; $\ddagger M R C$ Experimental Embryology and Teratology Unit, Woodmansterne Road, Carshalton, Surrey SMS 4EF, UK; and §Organic Synthesis Department, BioCarb AB, S-223 70 Lund, Sweden

\begin{abstract}
Summary. Mouse blastocysts bound LNF I conjugated to BSA-FITC or HSA-FITC and binding was inhibited by LNF I-HSA and to some extent by free LNF I, suggesting that the trophectoderm carries receptors specific for LNF I-like structures previously shown to be involved in implantation.
\end{abstract}

Keywords: embryo; implantation; neoglycoprotein; receptor; trophoblast, mouse

\section{Introduction}

Cell surface glycoconjugates have been implicated in cell-cell adhesion in a number of biological systems (Harrison \& Chesterton, 1980; Damsky et al., 1984; Edelman et al., 1985; Öbrink et al., 1986; Schachner, 1989) and carbohydrate moieties appear to be directly involved in several cellular processes in mammalian reproductive biology, e.g. binding of spermatozoa to the zona pellucida (Ahuja, 1985; Wassarman, 1989), the interaction of cells in preimplantation mouse embryos (Bird \& Kimber, 1984; Fendersen et al., 1984; Kimber, 1988), the adhesion between cells of the uterine epithelium (Dutt et al., 1987) and the initial attachment of the blastocyst to the uterine epithelium (Kimber et al., 1988; Lindenberg et al., 1988). To investigate the latter process we have used an invitro model, the attachment of mouse blastocysts to monolayers of uterine epithelial cells. In this system we have shown that a pentasaccharide, lacto-N-fucopentaose I (LNF I), specifically inhibits the attachment of the trophoblast to uterine cells, while other related oligosaccharides have no effect (Lindenberg et al., 1988). This oligosaccharide determinant has been demonstrated on the cell surface of the uterine epithelium during the pre-implantational phase of pregnancy, and also on the monolayers but not on the trophectoderm (Kimber \& Lindenberg, 1990). We interpret these findings to indicate that initial blastocyst attachment is dependent on interaction between a receptor on the trophectoderm and a glycoconjugate carrying LNF I-like structures on the uterine surface.

This present paper reports further evidence for the presence of a receptor for this oligosaccharide on the trophectoderm. We previously identified the LNF I-like and other carbohydrate structures on the endometrial epithelium by using monoclonal antibodies recognizing these carbohydrate structures. We have now used modified sugar probes to detect receptors for oligosaccharides on the embryonic cell surface. To be certain that the probes retain structural similarity to the endometrial oligosaccharides we have tested their ability to inhibit binding of the antibodies known to recognize the endometrial carbohydrate structures to sections of mouse uterus.

\section{Materials and Methods}

Animals. The mice were F1 B6D2F1/BOM hybrids (from the Laboratory of Animal Breeding and Research Center, Gl. Bomholdt Grd, Ltd, 8680 Ry, Denmark) as reported previously (Lindenberg et al., 1988). Female mice were 
injected intraperitoneally with 5i.u. PMSG (Antex, Leo Pharmaceuticals, Copenhagen, Denmark) at 09:00 h followed $48 \mathrm{~h}$ later by injection of $2.5 \mathrm{i}$.u. hCG (Physex, Leo) to induce superovulation. They were caged with males and left overnight. Mating was confirmed on the following morning by the presence of a vaginal plug. The day of observation of the vaginal plug was designated as Day 1 of pregnancy.

Embryo culture. Female mice were either killed on Day 2 of pregnancy and 2-cell embryos were flushed from the isolated oviducts, or on Day 4 or 5 of pregnancy and embryos were flushed from the uteri.

Embryos were handled outside the $\mathrm{CO}_{2}$ incubator in Ham's F-10 medium supplemented with Hepes buffer, 20 mM (Flow Laboratories, Rickmansworth, Herts WD13 IPQ, UK; cat. No. 16-884-49) and containing 4 mg bovine serum albumin $/ \mathrm{ml}$. Two-cell embryos were cultured in Earle's balanced salt solution supplemented with $2 \%$ Ultrose (IBF, 92390 Villeneuve-la-Garenne, France) in 4-well culture dishes (NUNC A/S, DK-400, Roskilde, Denmark) as previously reported (Lindenberg et al., 1988), or in Medium $16+4 \%$ bovine serum albumin (Whittingham, 1971) under oil.

Oligosaccharides. The oligosaccharides were supplied by BioCarb AB (Lund, Sweden) and were purified from human milk. They were chemically modified in two ways, to the alditols by treatment with sodium borohydride, or to the $\mathrm{N}$-acetylated 1-deoxy-1-(4-trifluoroacetamidophenyl)aminoalditols (TFAC derivatives; see Tables 1 and 2; Kallin et al., 1988).

Table 1. Structures of LNF I, alditol derivatives and

TFAC derivatives of oligosaccharides, used in this study

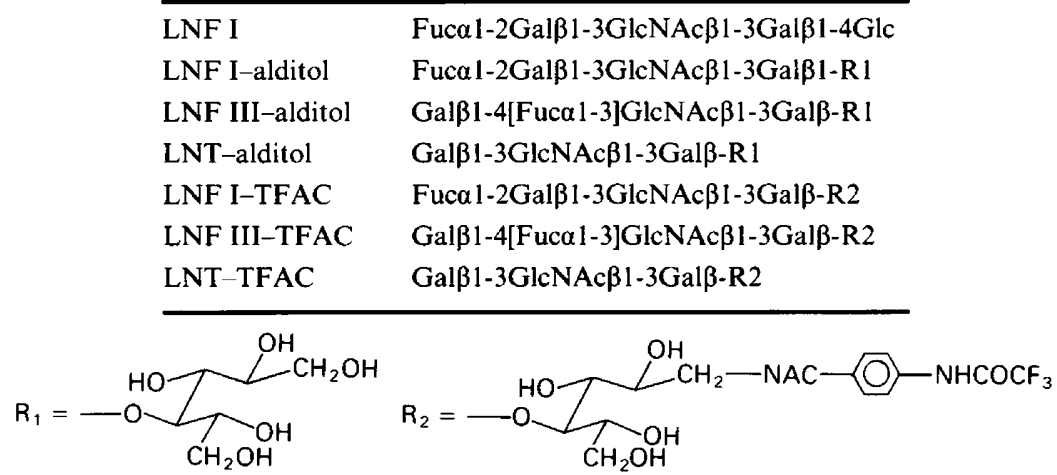

Table 2. Properties of BSA/HSA-FITC conjugated sugars

\begin{tabular}{lcccc}
\hline & $\begin{array}{c}\text { Protein } \\
\text { conc. } \\
(\mathrm{mg} / \mathrm{ml})\end{array}$ & $\begin{array}{c}\text { Mol. FITC/ } \\
\text { mol. BSA/HSA }\end{array}$ & $\begin{array}{c}\text { Mol. sugar/ } \\
\mathrm{mol} \text {. BSA/HSA }\end{array}$ & $\begin{array}{c}\text { Final protein } \\
\text { conc. } \\
(\mathrm{mg} / \mathrm{ml})\end{array}$ \\
\hline LNF I-BSA-FITC & 0.61 & 1.62 & $10-20$ & 0.41 \\
LNT-BSA-FITC & 1.65 & 0.53 & $10-20$ & $1 \cdot 10$ \\
LNF III-BSA-FITC & 0.98 & 1.66 & $10-20$ & 0.65 \\
\hline
\end{tabular}

Statistical evaluation of the results. For statistical evaluation we used the Mantel-Haenszel X-test for paired data, and tests having $P$ values of less than 0.02 were regarded as statistically different from controls.

Inhibition of antibody binding by oligosaccharides and their derivatives. Mouse monoclonal antibodies (IgM) (Table 3) with known carbohydrate specificity were provided as supernatants with an approximate concentration of $100 \mu \mathrm{g}$ immunoglobulin/ml by BioCarb AB (Lund, Sweden). Supernatants containing the antibodies (667/9E9, H001 and $630 / 7 \mathrm{Hl}$ ) were used to stain frozen sections of mouse uterus in a double-layer technique using a FITC-labelled second antibody as previously described (Kimber et al., 1988). Staining took place using the minimum antibody concentration required to give maximum specific binding in the presence or absence of oligosaccharides or modified oligosaccharides according to the regimen in Table 3.

Stained sections were viewed using a Zeiss or Leitz epi-fluorescence microscope with a mercury source for illumination and excitation filter BP 450-490 and suppression filter LP 515 and photographed.

Staining of blastocysts with oligosaccharide-bovine serum albumin/human serum albumin-fluorescein isothiocyanate ( $B S A / H S A-F I T C)$ conjugates. FITC-BSA or -HSA conjugates of oligosaccharides with protein:sugar molar ratios, fluorescein:protein ratios and protein concentrations as noted in Table 2 were obtained from BioCarb $\mathrm{AB}$ (Lund). 
These conjugates were synthesized by conversion of the TFAC derivatives to the corresponding isothiocyanates (Kallin et al., 1986), which were then reacted with albumin solutions (Smith et al., 1978; Svensson \& Lindberg, 1979). The sugar-albumin conjugates were labelled with fluorescein isothiocyanate according to standard procedures (Albini et al., 1984).

Blastocysts on Day 4, 5 or 6 of pregnancy were stained after culture from the 2-cell stage or directly after flushing from the uterus. When necessary the zona pellucida was removed with acid Tyrode's solution, $\mathrm{pH} 2 \cdot 5$. Embryos were washed 3 times in Medium M2 $+4 \mathrm{mg} \mathrm{BSA} / \mathrm{ml}$ (Quinn et al., 1982) and transferred to the sugar-serum albuminFITC conjugates either diluted in Medium M2 $+4 \% \mathrm{BSA}+0.02 \%$ sodium azide but without phenol red or in the same medium containing $5-10 \mathrm{mg} / \mathrm{ml}$ of the appropriate oligosaccharide to give the final concentration of the conjugate as noted in Table 2. Staining took place for $2 \mathrm{~h}$ at $20^{\circ} \mathrm{C}$. After washing in Medium M2 + BSA + azide they were mounted in optically true microslides (CAMLAB, Cambridge, UK) and viewed.

To examine the specificity of binding of the serum albumin-FITC-sugar conjugates, embryos were stained as outlined above, but in the presence of sugar-HSA conjugates, which were not labelled with fluorescein, at a final concentration of $0.05-0.35 \mathrm{~mm}$.

\section{Results}

\section{Staining of uterine epithelia}

The effect of oligosaccharides, their alditol derivatives and TFAC derivatives on staining of frozen sections of uterine epithelium with the monoclonal antibodies, $\mathrm{H} 001,630 / 7 \mathrm{H} 1$ and $667 / 9 \mathrm{E} 9$ is shown in Table 3.

Table 3. Effect of oligosaccharides, alditol derivatives and TFAC derivatives on staining of sections of mouse uterine epithelium (2-3 trials)

\begin{tabular}{lccc}
\hline & \multicolumn{3}{c}{ Antibodies (specificity) } \\
\cline { 2 - 4 } $\begin{array}{l}\text { Saccharide or } \\
\text { derivative }\end{array}$ & $\begin{array}{c}667 / 9 \mathrm{E} 9 \\
(\text { LNF I) }\end{array}$ & $\begin{array}{c}630 / 7 \mathrm{HI} \\
\text { (LNF III) }^{*}\end{array}$ & $\begin{array}{c}\text { HOOI } \\
\text { (LND I, } \dagger \text { LN-neo-DI } \ddagger)\end{array}$ \\
\hline- & ++ & +++ & +++ \\
LNF III & ++ & - & +++ \\
LNF I & $+/-$ & +++ & +++ \\
LNT & ++ & +++ & +++ \\
LNF III-alditol & ++ & - & +++ \\
LNF I-alditol & + & ++ & +++ \\
LNT-alditol & ++ & +++ & +++ \\
LNF III-TFAC & ++ & - & ++ \\
LNF I-TFAC & $+1-$ & +++ & +++ \\
LNT-TFAC & ++ & +++ & \\
*See Table 1. & & & ++ \\
†Lacto-N-difucohexaose I. & &
\end{tabular}

In the absence of added sugars, Antibodies 667/9E9, H001 and 630/7H1 all stained the uterine luminal and glandular epithelia on Days 4 and 5 of pregnancy as previously reported (Kimber et al., 1988). Binding of Antibodies $\mathrm{H} 001$ and $630 / 7 \mathrm{H} 1$ was affected by the oligosaccharides and oligosaccharide derivatives as expected from the known sugar specificity. However, the LNF ITFAC derivative caused a slight reduction in amount of Antibody $\mathrm{H} 001$ bound and LNF I-alditol diminished staining with Antibody $630 / 7 \mathrm{H} 1$ on the uterine epithelium to some extent.

As found previously, in the presence of LNF I staining of the glands with Antibody 667/9E9 was considerably reduced. On Day 4 of pregnancy the staining of the epithelium was similarly reduced by at least $75 \%$ in the presence of LNF I, while on Day 5 staining was completely abolished. When staining with Antibody 667/9E9 took place in the presence of LNF I-alditol there was a slight reduction in antibody binding to the glands and staining of the epithelium was decreased by approximately $25 \%$. 
In contrast, in the presence of the LNF I-TFAC derivative binding of 667/9E9 was greatly reduced or absent in the glands and epithelium. The LNF III- and LNT-TFAC derivatives had no effect.

\section{Staining of blastocysts with oligosaccharide-BSA-FITC conjugates}

In a preliminary study we examined binding by embryos of LNF I conjugated via the aminoalditol to FITC. Some indication of fluorescent staining of cultured embryos on Day 5 or Day 6 of development could be demonstrated using this conjugate. However, since we did not observe consistent binding with the monovalent FITC-sugar, we attempted to increase the affinity of binding by using the multivalent FITC-labelled neoglycoprotein LNF I-TFAC-BSA-FITC. Furthermore, since the TFAC derivative was as effective as the underivatized sugar but the alditol derivative was rather ineffective in inhibiting binding of monoclonal Antibody 667/9E9 to the endometrial epithelium, it appeared that derivitization with TFAC may retain the normal three dimensional structure of the sugar better than the alditol.

On Day 4 of pregnancy cultured early blastocysts did not bind LNF I-BSA-FITC. Very few cultured embryos bound this conjugate on the morning of Day 5 but by the afternoon of Day 5 about $29 \%$ of the embryos bound the conjugate. By Day 6 ( $5 \frac{1}{2}$ days of development) the percentage had increased to $76 \%$ (Table 4).

Table 4. Appearance of binding sites for LNF I-BSA-FITC on cultured mouse embryos during pre- and peri-implantation development

\begin{tabular}{|c|c|c|c|c|}
\hline \multirow{3}{*}{$\begin{array}{l}\text { Source } \\
\text { of embryos }\end{array}$} & \multicolumn{4}{|c|}{$\begin{array}{l}\text { No. of embryos stained/ } \\
\text { total no. of embryos examined (\%) }\end{array}$} \\
\hline & \multirow{2}{*}{$\begin{array}{c}\text { Day } 4 \\
\text { p.m. }\end{array}$} & \multicolumn{2}{|c|}{ Day 5} & \multirow{2}{*}{$\begin{array}{l}\text { Day } 6 \\
\text { a.m. }\end{array}$} \\
\hline & & a.m. & p.m. & \\
\hline Cultured & $0 / 18(0)$ & $15 / 95(16)$ & $28 / 96(29)$ & $111 / 146(76)$ \\
\hline Uterine & $0 / 22(0)$ & $24 / 37(65)$ & - & - \\
\hline
\end{tabular}

To investigate the presence of receptors for LNF I-like determinants on uterine blastocysts at the time of implantation we flushed embryos from the uterus on the morning of Days 4 and 5 of development and stained them with LNF I-BSA-FITC. On the morning of Day 4 of pregnancy no embryo bound LNF I-BSA-FITC, but on the morning of Day $565 \%$ of the hatched blastocysts were stained (Table 4). In the presence of free LNF I the staining was significantly reduced $(P<0.05)$ and only $21 \%(8 / 38)$ of the blastocysts were postive.

Cultured Day- 6 blastocysts were divided into 3 categories (Table 5), those which retained their zonae pellucidae (unhatched), those which were emerging from the zona pellucida (hatching) and those which were free of the zona (hatched). The results of incubating blstocysts with 3 sugars conjugated to BSA-FITC are included in Table 5. LNF I-BSA-FITC bound to almost $100 \%$ of the hatched blastocysts, $83 \%$ of those blastocysts which were hatching but to less than one half of those blastocysts retained within the zona pellucida. Staining at the abembryonic pole with the conjugate varied from several cells to the entire mural trophectoderm (Fig. 1). LNF III-BSA-FITC stained $75 \%$ of the hatched blastocysts, $40 \%$ of those which were hatching and $50 \%$ of the unhatched blastocysts. In contrast, $<25 \%$ of the hatching blastocysts and none of the unhatched blastocysts bound LNT-BSA-FITC, while $41 \%$ of the hatched blastocysts reacted with this conjugate. 

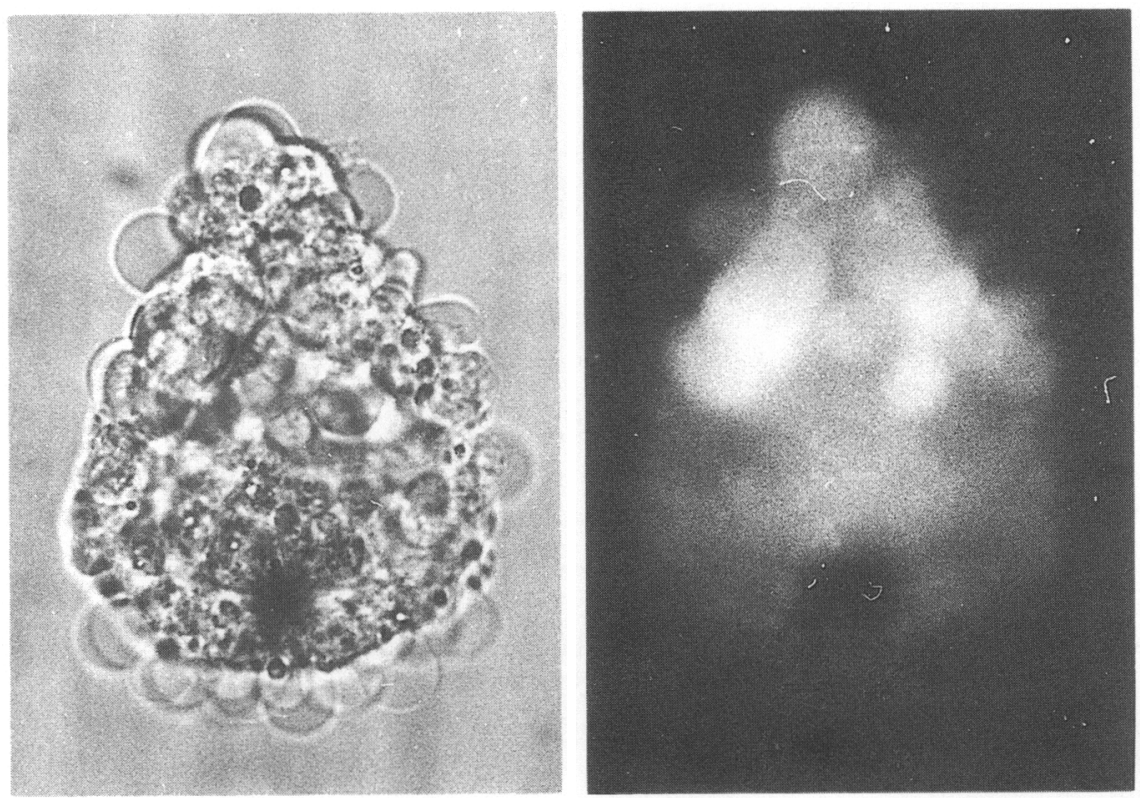

Fig. 1. Cultured Day-6 blastocyst stained with LNF I-BSA-FITC, showing binding to the cell surface of the abembryonic trophectoderm.

Table 5. Staining of cultured Day-6 blastocysts with oligosaccharide-BSA-FITC conjugates

\begin{tabular}{lrrr}
\hline & \multicolumn{3}{c}{$\begin{array}{c}\text { No. of embryos stained/ } \\
\text { total no. of embryos examined (\%) }\end{array}$} \\
\cline { 2 - 4 } Conjugate & \multicolumn{3}{c}{ Stage of blastocyst } \\
\cline { 2 - 4 } & Hatched & Hatching & Unhatched \\
\hline LNF I-BSA & $67 / 70(96)$ & $35 / 42(83)$ & $16 / 35(46)$ \\
LNF III-BSA & $29 / 40(73)$ & $19 / 47(40)$ & $12 / 24(50)$ \\
LNT-BSA & $13 / 32(41)$ & $9 / 38(24)$ & $0 / 27(0)$ \\
\hline
\end{tabular}

When we considered only hatched and hatching Day- 6 blastocysts, binding of LNF I-BSAFITC was found to be specific. The percentages of blastocysts which bound the conjugate in the presence of free LNF I was reduced from $87 \%$ to $52 \%$ (Table 6). In contrast, LNT caused no inhibition of LNF I-BSA-FITC binding to hatched and hatching blastocysts. Binding of LNTBSA-FITC to hatched or hatching blastocysts was low both in the absence and in the presence of all added oligosaccharides (Table 6).

To investigate further the specificity of the conjugate-blastocyst interaction we attempted to inhibit binding of the LNF I-albumin-FITC conjugate to embryos by carrying out the incubation in the presence of HSA sugar conjugates which were not FITC-labelled. Competitive inhibition of binding by sugar HSA-FITC and sugar BSA-FITC with sugar HSA conjugates yielded identical results. Therefore, Table 7 includes combined data for both types of albumin-FITC conjugate. When embryos cultured to Day 6 of development were stained with LNF I-albumin-FITC in the presence of $0.1 \mathrm{mM}$-LNF I-HSA, staining of almost all blastocysts was abolished. The reduction in 
Table 6. Effect of free oligosaccharides on binding of oligosaccharide-BSA-FITC conjugates to cultured Day-6 hatched and hatching mouse blastocysts

\begin{tabular}{lccc}
\hline & \multicolumn{3}{c}{$\begin{array}{c}\text { No. of embyros stained/ } \\
\text { total no. of embryos examined (\%) }\end{array}$} \\
\cline { 2 - 4 } & \multicolumn{2}{c}{ Oligosaccharide added (5 mM) } \\
\cline { 2 - 4 } FITC & & LNF I & LNT \\
\hline conjugate & - & $64 / 124$ & $39 / 46$ \\
LNF I-BSA & $111 / 128$ & $(52)$ & $(85)$ \\
& $(87)$ & $20 / 73$ & $19 / 72$ \\
LNT-BSA & $17 / 63$ & $(27)$ & $(26)$ \\
\hline
\end{tabular}

the proportion of blastocysts stained was statistically significant $(P<0.0001)$, compared to that seen in the absence of competing LNF I-HSA or in the presence of LNT-HSA. Binding of LNT-BSA-FITC to blastocysts was low in the absence or in the presence of either sugar conjugate. There was a marginally significant inhibition of binding in the presence of LNT-HSA $(P<0.05)$.

Table 7. Effect of oligosaccharide-HSA conjugates on binding of oligosaccharide-BSA/HSA-FITC conjugates to cultured Day-6 hatched and hatching blastocysts

\begin{tabular}{lccr}
\hline & \multicolumn{3}{c}{$\begin{array}{c}\text { No. of embryos stained/ } \\
\text { total no. of embryos examined (\%) }\end{array}$} \\
\cline { 2 - 4 } FITC conjugate & - & LNF I-HSA & LNT-HSA \\
\hline LNF I-BSA/HSA & $65 / 87(75)$ & $7 / 97(7)$ & $50 / 86(58)$ \\
LNT-BSA/HSA & $18 / 47(38)$ & $9 / 45(20)$ & $9 / 60(15)$ \\
\hline
\end{tabular}

\section{Discussion}

Lindenberg et al. (1988) demonstrated that LNF I, but not related sugars, inhibits the initial attachment of mouse blastocysts to uterine epithelial monolayers and they suggested that the pentasaccharide exerts its activity at the cell surface by blocking a receptor on the trophectoderm which normally interacts with a glycoconjugate carrying LNF I-like structures on the uterine surface. This very simple model is shown in Fig. 2.

Here, we report binding of multivalent LNF I-BSA/HSA-FITC to the surface of cultured Day 5-6 and uterine Day 5 mouse embryos, lending weight to this hypothesis. Binding was specifically inhibited by the unlabelled LNF I-HSA conjugate. The ability of the LNF I-HSA conjugate but not the pentasaccharide to inhibit effectively binding of the labelled conjugate can be explained when it is remembered that the multivalent neoglycoprotein probably exhibits a much stronger binding for receptors than a monovalent sugar (many orders of magnitude greater; Stowell \& Lee, 1978; Sarkar et al., 1979; Baenziger \& Maynard, 1980; Fenderson et al., 1984). If this is the case, one would predict that the 'multivalent' BSA-TFAC sugars would be more potent than the pentasaccharide in inhibiting binding of blastocysts to uterine epithelial cells. We are currently testing 


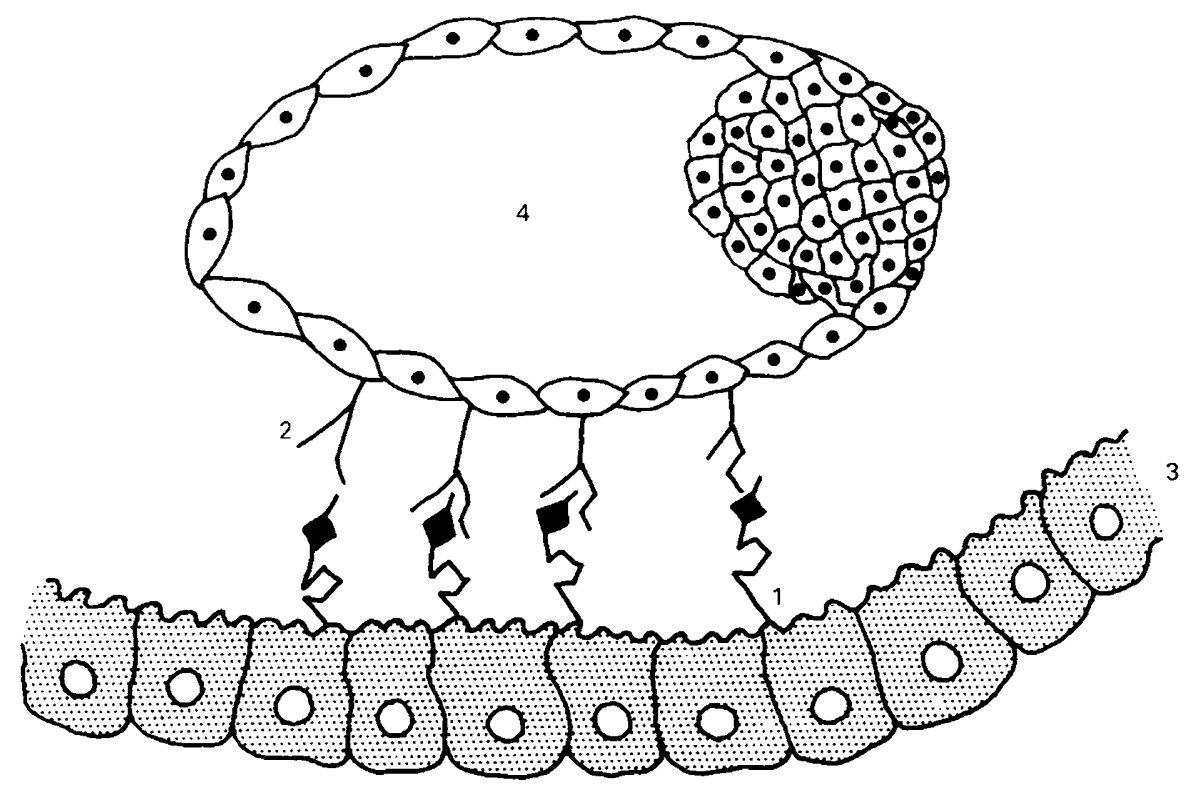

Fig. 2. Simplified model for initial attachment of the blastocyst (4) to the uterine endometrial epithelium (3). Receptors (2) on the trophoblast surface interact with lacto- $\mathrm{N}$-fucopentaose I determinants (1) present on the luminal epithelial surface, thus anchoring the embryo by its abembryonic surface.

this possibility. It is noteworthy that the free pentasaccharide reduced the proportion of blastocysts attaching to the endometrial epithelium in vitro (Lindenberg et al., 1988) to approximately the same extent that it reduced the proportion of hatched and hatching blastocysts which bound FITC-LNF I-HSA.

LNF I-BSA-FITC did not bind to cultured Day-4 blastocysts or morulae and bound to only a small proportion of cultured blastocysts on Day 5 of development. However, by Day 6 the majority of hatched and hatching blastocysts bound the conjugate (Tables $5 \& 6$ ), suggesting that receptors for this sugar appear on the surface of the trophectoderm between Days 5 and 6 of development in culture. Embryos flushed directly from the uterus on the morning of the day of implantation in utero (Day 5) bound LNF I-BSA-FITC in proportions similar to those of cultured Day-6 embryos. This demonstrates that the receptor is present on the morning of implantation in utero, and that cultured blastocysts lag behind uterine blastocysts in the appearance of the receptor. Furthermore, LNF I-BSA-FITC reacted with the abembryonic polar trophectoderm, the region of the mouse embryo which first contacts the uterine surface.

We previously showed that a monoclonal antibody, 667/9E9, recognizing the LNF I determinant binds to the surface of the uterine epithelium of the pregnant mouse. In this paper we have confirmed the specificity of this antibody and shown that certain modifications of the LNF I sugar (TFAC) but not others (alditol) retain the structural characteristics necessary for the antibody and perhaps other receptors to bind. However, the monoclonal antibody $630 / 7 \mathrm{H} 1$ is efficiently inhibited by both the alditol and TFAC derivatives, showing that the changes introduced by this type of modification are in some cases compatible with antibody binding.

In several systems the influence on cell interaction of oligosaccharides or polysaccarides has been reported (e.g. Misevic et al., 1987; DeAngelis \& Glaube, 1987). One of these is the mouse preimplantation embryo in which LNF III (Bird \& Kimber, 1984) or its lysyl-lysine conjugate (Fenderson et al., 1984) reverses the close cell-cell adhesion of the 8-16-cell morula. It is not known 
whether derivatives of LNF III, conjugated to HSA or BSA, will interfere more efficiently with the interaction between these cells, or whether chemical modification of the sugar prevents this. Experiments testing the influence of LNF I derivatives on the blastocyst-endometrial interaction are currently in progress.

Few studies have been carried out in which the influence on biological activity of chemically modifying a glycoconjugate or oligosaccharide has been examined. It has been shown that, although deglycosylation of the glycoprotein gonadotrophins does not affect binding of these hormones to their receptors, the subsequent receptor-adenylate cyclase coupling is disrupted (see Sairam, 1985). In contrast, hepatocyte receptors responsible for binding circulating glycoproteins recognize the carbohydrate moieties of these molecules, specifically terminal Gal residues. Conversion of B-D-Gal and B-D-Glc to the thio-neoglycoproteins or amidino-neoglycoproteins (Krantz et al., 1976; Stowell \& Lee, 1978; Stowell et al., 1980; Kawaguchi et al., 1981) allowed their binding by receptors on rat or rabbit hepatocytes or hepatic membranes. Results obtained from studies using both neoglycoproteins and natural proteins has led to similar conclusions about the sugar specificity of the receptors in this system (Pricer \& Ashwell, 1971; Hudgin et al., 1974; Ashwell \& Morell, 1974; Sarkar et al., 1979; Ashwell \& Harford, 1982; Lee, 1989).

In conclusion, our observation that the multivalent neoglycoprotein LNF I-BSA binds specifically to the surface of the abembryonic trophectoderm is in accord with the proposed interaction between a trophectoderm receptor and uterine epithelial glycoconjugates carrying H-type I structures at implantation.

We thank Helle Henriksen for skilled technical assistance during the course of this work; and Dr T. Andersson (BioCarb) for valuable discussions and encourgement. This work was supported by BioCarb AB (Lund, Sweden), the Danish Medical Research Council, the British Medical Research Council and the Brandt Brandtved Foundation, Denmark.

\section{References}

Ahuja, K.K. (1985) Carbohydrate determinants involved in mammalian fertilization. Am. J. Anat. 174, $207-222$.

Albini, B., Schauenstein, K. \& Wick, G. (1984) Immunofluorescence: principles and procedures. In Molecular Immunology, pp. 447-476. Eds Z. Atassi, C. Van Oss \& D. Absalon. Marcel Dekker, New York.

Ashwell, G. \& Harford, J. (1982) Carbohydrate-specific receptors of the liver. Ann. Rev. Biochem. 51, $531-554$.

Ashwell, G. \& Morrell, A.G. (1974) Role of surface carbohydrates in hepatic recognition and transport of circulating glycoproteins. Adv. enzymol. 41, 99-128.

Baenziger, J.U. \& Maynard, Y. (1980) Human hepatic lectins. J. biol. Chem. 255, 4607-4613.

Bird, J.M. \& Kimber, S.J. (1984) Oligosaccharides containing fucose linked $\mathrm{B}(1-3)$ and $\mathrm{B}(1-4)$ to $\mathrm{N}$-acetylglucosamine cause decompaction of mouse morulae. Devl Biol. 87, 267-276.

Damsky, C.H., Knudsen, K.A. \& Buck, C.A. (1984) Integral membrane proteins in cell-cell and cellsubstratum adhesion. In The Biology of Glycoproteins, pp. 1-66. Ed. R. J. Ivatt. Plenum Press, New York.

DeAngelis, P.L. \& Glabe, C.G. (1987) Polysaccharide structural features that are critical for the binding of sulfated fucans to Bindin, the adhesive protein from Sea Urchin Sperm. J. biol. Chem. 262, 13946-13952.
Dutt, A., Tang, J.-P. \& Carson, D.D. (1987) Lactosaminoglycans are involved in uterine epithelial cell adhesion in vitro. Devl Biol. 119, 27-37.

Edelman, G.M., Hoffman, S., Chuong, C.M. \& Cunningham, B.A. (1985) The molecular basis and dynamics of cell adhesion in embryo-genesis. In $\mathrm{Mol}$ ecular Determinants of Animal Form (UCLA, Symp. Molec. Cell. Biol. New Series), vol. 31, pp. 195-221. Allan R. Liss, New York.

Fenderson, B.A., Zehavi, U. \& Hakomori, S.-I. (1984) A multivalent lacto-N-fucopentaose-III-lysyllysine conjugate decompacts preimplantation mouse embryos while the free oligosaccharide is ineffective. $J$. exp. Med. 160, 1591-1516.

Harrison, F.L. \& Chesterton, C.J. (1980) Factors mediating cell-cell recognition and adhesion. FEBS Lett. 122, 157-165.

Hudgin, R., Pricer, W.E. \& Ashwell, G. (1974) The isolation and properties of a rabbit liver binding protein specific for asialoglycoproteins. J. biol. Chem. 249, 5536-5543.

Kallin, E., Lnn, H. \& Norberg, T. (1986) New derivatization and separation procedures for reducing oligosaccharides. Glycoconjugate J. 3, 311-319.

Kallin, E., Lnn, H. \& Norberg, T. (1988) Derivatization procedures for reducing oligosaccharides, part 2: chemical transformation of 1-deoxy-1-(4-trifluoroacetamidophenyl) aminoalditols. Glycoconjugate $J .5$, 145-150.

Downloaded from Bioscientifica.com at 04/26/2023 10:48:51AM 
Kawaguchi, K., Kuhlenschmidt, M., Rosemann, S. \& Lee, Y.C. (1981) Differential uptake of D-galactosyland D-glucosyl-neoglycoproteins by isolated rat hepatocytes. J. biol. Chem. 256, 2230-2234.

Kimber,S.J. (1988) The role of fucosylated glycoconjugate in cell-cell interactions of the mammalian preimplantation embryo. In Eukaryote Cell Recognition, pp. 194-224. Eds G. P. Chapman, C. Ainsworth \& C. Chatham. Cambridge University Press.

Kimber, S.J. \& Lindenberg, S, (1990) Hormonal control of a carbohydrate epitope involved in implantation in mice. J. Reprod. Fert. 89, 13-21.

Kimber, S.J., Lindenberg, S. \& Lundblad, A. (1988) Distribution of some Gal B(1-3(4)) GlcNAc related carbohydrate antigens on the mouse uterine epithelium in relation to the peri-implantational period. $J$. Reprod. Immunol. 12, 297-313.

Kratz, M.J., Holtzman, N.A., Stowell, C.P. \& Lee, Y.C. (1976) Attachment of thioglycosides to proteins: enhancement of liver membrane binding. Biochemistry, NY 15, 3963-4908.

Lee, Y.C. (1989) Binding modes of mammalian hepatic Gal/GalNAc receptors. In Carbohydrate Recognition in Cellular Function (Ciba Fdn Symp. 145), pp. 80-95. Wiley, Chichester.

Lindenberg, S., Sundberg, K., Kimber, S.J. \& Lundblad, A. (1988) The milk oligosaccharide lacto-N-fucopentaose I, inhibits attachment of mouse blastocysts on endometrial monolayers. J. Reprod. Fert. 83, 149-158.

Misevic, J.N., Finne, J. \& Burger, M.M. (1987) Involvement of carbohydrates as multiple low affinity interaction sites in the self-association of the aggregation factor from the marine sponge Microciona prolifera. J. biol. Chem. 262, 5870-5877.

Öbrink, B., Odin, P., Tingstrm, A., Hansson, M., Rubin, K. \& Blinkstad, I. (1986) Cell adhesion molecules involved in cell-cell adhesion phenomena. Structure and function of cell CAM 105. In Biology and Pathology of Platelet-Vessel Wall Interactions, pp. 161-180. Eds G. Jolles, Y. Legrand \& A. Nurden. Academic Press, New York.
Pricer, W. \& Ashwell, G. (1971) The binding of desialylated glycoproteins by plasma membrane of rat liver. J. biol. Chem. 246, 4825-4833.

Quinn, P., Barros, C. \& Whittingham, D.G. (1982) Preservation of hamster oocytes to assay the fertilizing capacity of human spermatozoa. J. Reprod. Fert. 66, 161-168.

Sairam, M.R. (1985) Protein glycosylation and receptorligand interactions. In The Receptors, vol. 2, pp. 307-340. Ed. P. M. Conn. Academic Press, New York.

Sarkar, M., Liao, J., Kabat, A., Tanabe, T. \& Ashwell, G. (1979) The binding site of rabbit hepatic lectins. $J$. biol. Chem. 254, 3170-3174.

Schachner, M. (1989) Families of neural adhesion molecules. In Carbohydrate Recognition in Cellular Function (Ciba Fdn Symp. No. 145), pp. 156-172. Wiley, Chichester.

Smith, D.F., Zopf, D.A. \& Ginsburg, V. (1978) Carbohydrate antigens: Coupling of oligosaccharide phenethylamine-isothiocyanate derivatives to bovine serum albumin. Methods Enzymol. 50, 169-171.

Stowell,C.P.\& Lee, Y.C. (1978) The binding of D-glucosylneoglycoproteins to the hepatic asialoglycoprotein receptor. J. biol. Chem. 253, 6107-6110.

Stowell, C.P., Lee, R.T. \& Lee, Y.C. (1980) Studies on the specificity of rabbit hepatic carbohydrate-binding protein using neoglycoproteins. Biochemistry, NY 19, $4904-4908$.

Svensson, S.B. \& Lindberg, A.A. (1979) Coupling of acid labile Salmonella specific oligosaccharides to macromolecular carriers. J. Immunol Methods 25, 323-335.

Wassarman, P.W. (1989) Role of carbohydrates in receptor mediated fertilization in mammals. In Carbohydrate Recognition in Cellular Function (Ciba Fdn Symp. No. 145), pp. 135-155. Wiley, Chichester.

Whittingham, D.G. (1971) Culture of mouse ova. $J$. Reprod. Fert., Suppl. 14, 7-21.

Received 30 August 1989 